\title{
The computational structure of environmental life cycle costing
}

\author{
Vincent Moreau $^{1} \cdot$ Bo P. Weidema ${ }^{2}$
}

Received: 19 September 2014 / Accepted: 10 August 2015 /Published online: 25 August 2015

(C) Springer-Verlag Berlin Heidelberg 2015

\begin{abstract}
Purpose Existing computational methods for life cycle costing (LCC) are few and appeared inconsistent with the very definition of LCC. This article improves the common matrixbased approach in life cycle assessment as applied to LCC, correcting previous errors.

Methods Reusing a simple and hypothetical example, the authors derive the LCC from both the physical and monetary technology matrices. Accounting for the added value of all activities in the life cycle leads to a simplified computational structure for LCC.

Results and discussion The results show that the definition of LCC and computational structure can be fully harmonized with life cycle assessments (LCAs) and simplified. In addition to eco-efficiency calculations, the vector of added values, if disaggregated over social groups, allows for distributional analysis. It is furthermore shown how LCC can account for costs shifting (economic externalities) in the same way as LCA highlights shifting of environmental externalities between different products, life cycle stages or actors.

Conclusions Life cycle costing as defined by the sum of the added value over the life cycle is consistent with LCA and cradle to gate assessments in particular. The authors simplified
\end{abstract}

Responsible editor: Hanna-Leena Pesonen

Vincent Moreau

vincent.moreau@epfl.ch

1 School of Architecture, Civil and Environmental Engineering, Ecole Polytechnique Federale Lausanne, 1015 Lausanne, Switzerland

2 Department of Development and Planning, Aalborg University, Skibbrogade 5, 1, 9000 Aalborg, Denmark the computation of LCC with either the matrix-based approach or the added values of upstream activities as an elementary exchange vector or matrix.

Keywords Computational structure $\cdot$ Externalities $\cdot$ Life cycle assessment $\cdot$ Life cycle costing $\cdot$ Value added

\section{Background}

Research in the field of life cycle assessment (LCA) has gradually expanded towards economic and social aspects of production and consumption chains (Rebitzer and Hunkeler 2003). Despite the inherent differences between physical, economic and social metrics, several attempts to harmonize the methodological approaches have been made (Hunkeler et al. 2008; Swarr et al. 2011).

Historically, conventional life cycle costing (LCC) addressed only one stakeholder perspective, typically that of the user of products with either long life times or high maintenance costs, or both, in public procurement, for example. Environmental LCC, as defined by Hunkeler et al. (2008), assesses all costs associated with the life cycle of a product, incurred by one or more actors over the product's lifetime, including externalities which are foreseen to be internalized in the decision-relevant future. Heijungs et al. (2013) point out that the adjective "environmental" here does not imply the inclusion of external environmental costs nor does it restrict the costs to internal "environmental costs" (for e.g. waste prevention or disposal). It simply refers to the fact that the economic analysis has been made in a way that is consistent with the multi-stakeholder perspective of physical product life cycles in environmental LCA according to the ISO 14040 -series of standards, as opposed to conventional 
LCC that has a single-stakeholder perspective and "societal LCC" (Hunkeler et al. 2008), which includes also environmental costs to provide a fully monetarized life cycle sustainability assessment. LCC provides useful results for decision-making purposes: Cost hotspots at different stages of a product life cycle (Gadiesh and Gilbert 1998), eco-efficiency hotspots (environmental impact per value added) in the product life cycle (Goedkoop et al. 1999; Clift and Wright 2000) or as an essential part of overall life cycle-based cost-benefit assessments (life cycle sustainability assessments) to avoid burden shifting in general. The computational structure discussed below clarifies such issues as identified by Heijungs et al. (2013).

Heijungs et al. (2013) propose a computational structure for LCC on the basis of the computational structure of LCA. While we agree with the need for integrating LCC into the computational structure of LCA, we disagree with the proposal of Heijungs et al. (2013) on their definition of life cycle costs and the way these are calculated in their paper. In this article, we provide a different definition of life cycle costs and show how this leads to a simplified computational structure, which in fact lies nascent already in the proposal of Heijungs et al. (2013).

\section{LCC according to Heijungs et al. (2013)}

To illustrate LCC, Heijungs et al. (2013) use a simple and instructive example. We reproduced and reworked this example here to explain the difference between our approach and theirs.

The functional unit in the example is 1 year of sitting on a wooden chair. The life cycle is simplified to the five activities (processes): Production of electricity, production of wood, production of chair, use of the chair and disposal of broken chair. Heijungs et al. (2013) provided the physical amounts and prices of all flows in the system, as reproduced in Table 1.

Heijungs et al. (2013) set the price of sitting to zero, even though to obtain this service or utility, it is necessary to pay for producing the product and disposing it after use. The argument appears to be that "sitting" is "not a commodity that is exchanged on a market, so there is no price for it" (Heijungs et al. 2013, p. 1727). This then leads Heijungs et al. (2013) to find a negative value added for the use activity (see column 5 in Table 1). This "value lost" they then interpret as the life cycle cost: "we have defined the life cycle cost as the negative value added for the use process" (Heijungs et al. 2013, p. 1728).

This definition causes a problem for interpreting LCC in cradle-to-gate studies, e.g. studies on materials and components, such as steel, plastic, electricity and engines. Since such studies do not have a final use stage and the activity in which the product is used typically will be a production activity where revenues are greater than intermediate costs, the definition above would imply a negative life cycle cost. This leads Heijungs et al. (2013) to conclude that "Probably, the concept of life cycle cost for an incomplete life cycle doesn't make any sense at all" (Heijungs et al. 2013, p. 1730).

Using the normal matrix formulation as in LCA, the physical flows from column 2 in Table 1 can be represented in the physical technology matrix $\mathbf{A}_{p}$ and the final demand vector $\mathbf{f}_{p}$, allowing to calculate the scaling factors $\mathbf{s}$, all in accordance with Heijungs et al. (2013):

$$
\mathbf{A}_{p}=\left(\begin{array}{ccccc}
1 & 0 & -2 & 0 & 0 \\
0 & 1 & -5 & 0 & 0 \\
0 & 0 & 1 & -5 & 0 \\
0 & 0 & 0 & 5 & -1 \\
0 & 0 & 0 & 10 & 0
\end{array}\right) \quad \mathbf{f}_{p}=\left(\begin{array}{l}
0 \\
0 \\
0 \\
0 \\
1
\end{array}\right) \quad \mathbf{s}=\left(\mathbf{A}_{p}^{-1}\right) \mathbf{f}_{p}=\left(\begin{array}{c}
1 \\
2.5 \\
0.5 \\
0.1 \\
0.5
\end{array}\right)
$$

Table 1 Hypothetical data for the life cycle of a wooden chair

\begin{tabular}{|c|c|c|c|c|c|}
\hline Activity (process) & Product (1) & Physical amount (2) & Price (3) & Monetary amount (4) & Value added (5) \\
\hline Production of electricity & Electricity & $1 \mathrm{MJ}$ & $5 € / \mathrm{MJ}$ & $5 €$ & $5 €$ \\
\hline Production of wood & Wood & $1 \mathrm{~kg}$ & $1 € / \mathrm{kg}$ & $1 €$ & $1 €$ \\
\hline \multirow[t]{2}{*}{ Production of chair } & $\begin{array}{l}\text { Electricity } \\
\text { Wood }\end{array}$ & $\begin{array}{l}-2 \mathrm{MJ} \\
-5 \mathrm{~kg}\end{array}$ & $\begin{array}{l}5 € / \mathrm{MJ} \\
1 € / \mathrm{kg}\end{array}$ & $\begin{array}{l}-10 € \\
-5 €\end{array}$ & \multirow[t]{2}{*}{$10 €$} \\
\hline & Chair & 1 piece & $25 € /$ piece & $25 €$ & \\
\hline \multirow[t]{2}{*}{ Use of chair } & $\begin{array}{l}\text { Chair } \\
\text { Broken chair }\end{array}$ & $\begin{array}{r}-5 \text { pieces } \\
5 \text { pieces }\end{array}$ & $\begin{array}{l}25 € / \text { piece } \\
-2 € / \text { piece }\end{array}$ & $\begin{array}{l}-125 € \\
-10 €\end{array}$ & \multirow[t]{2}{*}{$-135 €^{*}$} \\
\hline & Sitting & 10 years & $0 € /$ year* & $0 €^{*}$ & \\
\hline Disposal of broken chair & Broken chair & -1 piece & $-2 € /$ piece & $2 €$ & $2 €$ \\
\hline
\end{tabular}

The first four columns are reproduced from Heijungs et al. (2013) and the last column sums the monetary amounts in column 4 for each activity. The values with an asterisk $\left(^{*}\right)$ for the activity "Use of chair" are different in our approach since we calculate a price for sitting of $13.5 € /$ year, so that the monetary value for 10 years is $135 €$ and the value added for the "Use of chair" becomes zero 
Heijungs et al. (2013) then use the prices from column 3 in Table 1 as a price vector $\alpha$ to derive the monetary technology matrix $\mathbf{A}_{m}$ and the final demand vector $\mathbf{f}_{m}$, as follows:

$$
\boldsymbol{\alpha}=\left(\begin{array}{c}
5 \\
1 \\
25 \\
-2 \\
0
\end{array}\right) \mathbf{A}_{m}=\operatorname{diag}(\boldsymbol{\alpha}) \mathbf{A}_{p}=\left(\begin{array}{ccccc}
5 & 0 & -10 & 0 & 0 \\
0 & 1 & -5 & 0 & 0 \\
0 & 0 & 25 & -125 & 0 \\
0 & 0 & 0 & -10 & 20 \\
0 & 0 & 0 & 0 & 0
\end{array}\right)
$$

$$
\mathbf{f}_{m}=\operatorname{diag}(\boldsymbol{\alpha}) \mathbf{f}_{p}=\left(\begin{array}{l}
0 \\
0 \\
0 \\
0 \\
0
\end{array}\right)
$$

Since sitting has zero price, $\mathbf{f}_{m}$ and the last line of $\mathbf{A}_{m}$ only contain zeroes. This has the unfortunate consequence that the monetary technology matrix becomes singular and thus noninvertible. This forces Heijungs et al. (2013) to use the physical scaling factors obtained as above from the physical technology matrix, for their further calculations, e.g. for the value added:

$$
\mathbf{v}=\mathbf{A}_{m, \text { scaled }}^{T} 1=\left(\begin{array}{c}
5 \\
2.5 \\
5 \\
-13.5 \\
1
\end{array}\right)
$$

\section{Corrected and simplified procedure}

As also pointed out by Heijungs et al. (2013), no feasible economy will tolerate activities with a negative value added. We thus regard the zero price of the reference product and the resulting negative value added of the use activity as a conceptual error. Correcting this error leads to a new definition of life cycle cost, a simplified computational structure and a wider applicability of LCC since the revised definition also applies to cradle-to-gate studies.

First, let us note that if the example chair was purchased and maintained by a third party that would then rent the chair to the user, this third party would indeed charge a hire price for its use. The fact that the user owns the chair does not change the fact that sitting has a value that may be determined on a market. The absence of a market does not make the price (value) disappear, it just requires it to be calculated, rather than directly observed. So in our approach, the price of sitting is calculated to $13.5 € /$ year ( $12.5 €$ for the chair and $1 €$ for its disposal), so that the monetary amount for 10 years of sitting becomes $135 €$ and the value added for the use activity becomes zero. The value added in the use stage may in principle be different from zero, but in this case, the user is neither paid nor taxed for sitting, and therefore, no further value is added to the product by its use here, and the price of sitting is therefore exclusively determined by the cost of the intermediate inputs (the chair and its disposal).

This gives a corrected price vector $\alpha$ as follows, with the corresponding monetary technology matrix $\mathbf{A}_{m}$ and monetary final demand vector $\mathbf{f}_{m}$ :

$$
\begin{aligned}
\boldsymbol{\alpha}=\left(\begin{array}{c}
5 \\
1 \\
25 \\
-2 \\
13.5
\end{array}\right) \mathbf{A}_{m}=\operatorname{diag}(\boldsymbol{\alpha}) \mathbf{A}_{p}= & \left(\begin{array}{ccccc}
5 & 0 & -10 & 0 & 0 \\
0 & 1 & -5 & 0 & 0 \\
0 & 0 & 25 & -125 & 0 \\
0 & 0 & 0 & -10 & 20 \\
0 & 0 & 0 & 135 & 0
\end{array}\right) \\
\mathbf{f}_{m} & =\left(\begin{array}{c}
0 \\
0 \\
0 \\
0 \\
13.5
\end{array}\right)
\end{aligned}
$$

The corrected monetary technology matrix is invertible, and inversion leads to the same scaling factors $\mathbf{s}$ as for the physical matrix, and a corrected scaled technology matrix:

$$
\mathbf{A}_{m, \text { scaled }}=\mathbf{A}_{m} \operatorname{diag}(\mathbf{s})=\left(\begin{array}{ccccc}
5 & 0 & -5 & 0 & 0 \\
0 & 2.5 & -2.5 & 0 & 0 \\
0 & 0 & 12.5 & -12.5 & 0 \\
0 & 0 & 0 & -1 & 1 \\
0 & 0 & 0 & 13.5 & 0
\end{array}\right)
$$

The corrected vector of added values $\mathbf{v}$

$\mathbf{v}=\mathbf{A}_{m, \text { scaled }}^{T} 1=\left(\begin{array}{c}5 \\ 2.5 \\ 5 \\ 0 \\ 1\end{array}\right)$

has a value added for sitting of zero instead of $-13.5 €$, while the sum of the $\mathbf{v}$ vector is $13.5 €$, namely the life cycle cost. In contrast to Heijungs et al. (2013), we thus define the life cycle cost as "the sum of all value added over the life cycle".

The above calculations show that if the costs of all activities are correctly accounted for, the same matrixbased approach can be applied to both physical and monetary flows. However, we do not need to go via the monetary matrix to obtain the life cycle costs. Observe that the value added for each activity was already given in column 5 of Table 1 and obtained without any matrix operations. All we have to do to obtain the life cycle costs is to 
extract this column 5 as a row vector $\mathbf{b}$ of value added and apply the scaling factors $\mathbf{s}$ to this vector:

$$
\mathbf{b}^{T}=\left(\begin{array}{c}
5 \\
1 \\
10 \\
0 \\
2
\end{array}\right) \quad \mathbf{v}=(\operatorname{bdiag}(\mathbf{s}))^{T}=\left(\begin{array}{c}
5 \\
2.5 \\
5 \\
0 \\
1
\end{array}\right)
$$

The $\mathbf{b}$ vector can be seen as one vector of the matrix of elementary exchanges (also known as the "emissions matrix" or in Heijungs et al. (2013) as the "intervention matrix" with processes as columns and emissions as rows). The life cycle cost will then automatically be calculated alongside all other elementary exchanges, such as "carbon dioxide" or "coal, in ground", when the scaling factors are applied to the matrix of elementary exchanges. This approach to computation of life cycle costs was applied in Weidema et al. (2008) which also give examples of situations where there is value added in the use stage. Ciroth and Franze (2009) show how to implement this approach in an LCA software. When data is available for this, the $\mathbf{b}$ vector of value added can be split up into its components: taxes, operating surplus, rent, and wages, which may even be further disaggregated by receiving social groups, whereby the information is ready for use in a distributional equity assessment.

\section{Discussion}

When accumulating data over a product life cycle, double counting is avoided by including the contribution from each activity in the life cycle only once. In the life cycle of a newspaper, the elementary exchanges from forestry are included in the accumulated exchanges of paper pulp, which is included in the accumulated exchanges of a newspaper, etc. Thus, it would not make sense to add the forestry exchanges once more to the accumulated paper pulp when calculating the accumulated newspaper impacts. In the same way, adding costs over the life cycle of a product would result in double counting. This is because cost is already an accumulated value. The cost of wood is included in the cost of pulp, which is

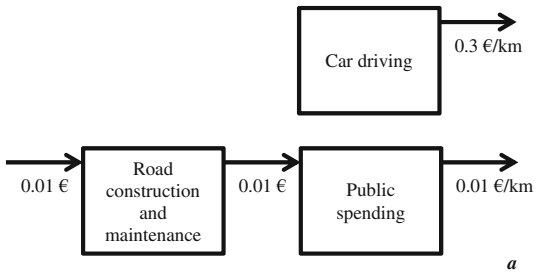

Fig. 1 Accounting for economic externalities in LCC. Part $a$ on the left shows the actual spending per kilometre of car driving. Part $b$ on the right shows the same activity modified for LCA and LCC calculation. The included in the cost of paper. So the life cycle cost is not the sum of these costs at each activity in a product life cycle, but rather the sum of the value added of each activity, i.e. the difference between the cost of the output and the cost of the intermediate inputs. This difference, the value added, represents the costs of primary factors for the activity, i.e. payments to tax, entrepreneurs, resource owners and labour. Value added summed over the upstream activities of a product is the cost of that product input for the next activity. The price of a product output is equal to the sum of the value added summed over all the upstream activities, including the value added of the activity itself. Thus, the life cycle cost also becomes a meaningful concept in a cradle-to-gate study. The sum of all value added over the life cycle is the life cycle cost of the product.

An important difference between traditional life cycle costing and environmental LCC is that the environmental LCC includes the costs of all activities that are physically linked to or caused by the life cycle of a product, irrespective of which actor is paying for these activities. For example, the user of a vehicle may not pay for the road use or the waste disposal of a vehicle, which may instead be paid over the general taxes. This is essentially a subsidy from the government to the vehicle user and thus an economic externality of the vehicle use. However, the road maintenance and the waste disposal are still physically linked to or caused by the vehicle use and thus part of the life cycle of vehicle use for which LCC are calculated. So the cost that was originally calculated as part of the government expenditure is now added to the vehicle use LCC. However, since the vehicle user still does not pay this cost, the shift of cost from the government to the vehicle user must be counterbalanced when accounting for the primary factors by subtracting the cost in the primary factors (taxes) paid by the vehicle user (i.e. representing the subsidy) and adding the cost to the primary factors of the government (since the costs are now calculated as a subsidy payment and no longer as a government payment to the suppliers of the road maintenance and vehicle disposal). This way of accounting for economic externalities, i.e. externalities that are already paid for by another actor than the actor that causes the costs, is illustrated in Fig. 1. In this way, LCC highlights costs

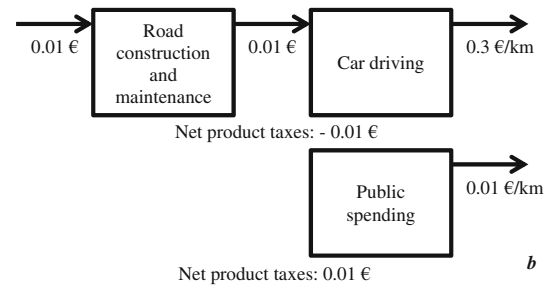

negative net product tax represents a subsidy, an economic externality, to the car driving activity 
shifting (economic externalities) in the same way as LCA pinpoints shifts of environmental externalities between different products, life cycle stages or actors.

With this form of accounting, the costs incurred by other stakeholders are made explicit. A similar picture would apply to the example of the chair if landfilling or incineration costs were borne by the government and paid for through taxes. The monetary matrix would then be augmented with a taxation process and net taxes and the computation of the life cycle costs or value added would still be done as in section 3 .

\section{Conclusions}

We define the life cycle cost as "the sum of all value added over the life cycle", as opposed to "the negative value added for the use process" given by Heijungs et al. (2013). When seen in relation to the definition by Hunkeler et al. (2008), quoted above in the background section, a more generic formulation of our definition would read: "the sum of the value added for each activity in the product life cycle for each and every actor involved, including externalities which are foreseen to be internalized in the decision-relevant future". As such, this definition provides a clear measure of what environmental LCC entails in practice.

In line with Heijungs et al. (2013), we note that the value added of an activity cannot be negative unless the activity is subsidized. This leads us to conclude that also final use activities must have a value added $\geq 0$ and that this value added can be calculated as the sum of the costs of the inputs to the final use activity. We conclude that the use of zero prices for the reference product of the use activity in Heijungs et al. (2013) is a conceptual error and the cause of the observed negative value added of the use activity.

Using the simple example from Heijungs et al. (2013), we show how correcting this conceptual error allows the same matrix-based approach to be applied to both physical and monetary flows and how the life cycle costs can be calculated by applying the scaling factors from the inverted technology matrix directly to the value added vector. By placing the value added vector as part of the matrix of elementary exchanges, the life cycle costs can then be calculated alongside all other life cycle results, such as "carbon dioxide" or "coal, in ground", when the scaling factors are applied to the matrix of elementary exchanges.

Our approach already lies nascent in the proposal of Heijungs et al. (2013), where a price vector is available for all flows in the technology matrix, since this implies that the value added is already inherent in the data for each activity in the life cycle and that a separate inversion of the monetary matrix is therefore unnecessary.

Ethical statement The work behind this article was prompted by Heijungs et al. (2013) and took place as part of the development of an advanced course in LCA given by the authors at the International Life Cycle Academy in Barcelona, Spain.

\section{References}

Ciroth A, Franze J (2009) Life cycle costing in SimaPro. GreenDeltaTC, Berlin

Clift R, Wright L (2000) Relationships between environmental impacts and added value along the supply chain. Technol Forecast Soc Chang 65(3):281-295

Gadiesh O, Gilbert JL (1998) Profit pools: a fresh look at strategy. Harv Bus Rev 76(3):139-147

Goedkoop MJ, van Halen CJG, te Riele HRM, Rommens PJM (1999) Product service systems, ecological and economic basics. Pré Consultants, Amersfoort

Heijungs R, Settanni E, Guinée J (2013) Toward a computational structure for life cycle sustainability analysis: unifying LCA and LCC. Int J Life Cycle Assess 18(9):1722-1733

Hunkeler D, Lichtenvort K, Rebitzer G (2008) Environmental life cycle costing. SETAC, Pensacola

Rebitzer G, Hunkeler D (2003) Life cycle costing in LCM: ambitions, opportunities, and limitations. Int J Life Cycle Assess 8(5):253-256

Swarr TE, Hunkeler D, Klöpffer W, Pesonen HL, Ciroth A, Brent AC, Pagan R (2011) Environmental life cycle costing: a code of practice. SETAC, Pensacola

Weidema B, Wesnaes M, Hermansen J, Kristensen T, Halberg N (2008) "Environmental improvement potentials of meat and dairy products.” EUR 23491. EU JRC institute for prospective technological studies 